\title{
Educação e desenvolvimento: modos de regulação dos sistemas educacionais
}

\author{
Marisa Ribeiro Teixeira Duarte*
}

\section{Resumo}

$\mathrm{Na}$ atualidade, o debate em torno do desenvolvimento brasileiro é adjetivado com o qualificativo de "social" em diversos documentos. Este artigo, mediante a análise de conteúdo de obras clássicas de Sociologia Educacional no País, estuda como se articulou o binômio "educação e desenvolvimento". A pesquisa, após sintetizar as proposiçóes sociológicas dos períodos anteriores, analisa três aspectos sobre Educação e Desenvolvimento, presentes no documento final da Conferência Nacional de Educação - CONAE, realizada no Brasil em 2010. Participaram da Conferência aproximadamente 5.000 educadores de diferentes regióes do País, sob a coordenação do Ministério da Educação. E seu documento final apresenta proposiçóes para a elaboração da Lei que aprova o Plano Nacional de Educação. O diagnóstico sobre o desenvolvimento do País constante no documento final da CONAE, e as funçóes atribuídas às instituiçóes educacionais e aos modos de planejamento subjacentes são analisados à luz da sociologia das regulaçôes sociais. $\mathrm{O}$ estudo conclui expondo vertentes analíticas esquecidas no documento da Conferência e orientador do Plano Nacional da Educação.

Palavras-chave: Tendências de política educacional. Encontros nacionais de planejamento. Desenvolvimento socioeconômico.

\footnotetext{
* Doutora em Educação pela Universidade Federal Fluminense - UFF. Professora do Departamento de Administração Escolar e pesquisadora do Programa de Pós-Graduação da Faculdade de Educação da Universidade Federal de Minas Gerais. Apoio de pesquisa: Cátedra IPEA Anísio Teixeira.
} 


\section{Educação e desenvolvimento: modos de regulação dos sistemas educacionais}

Só com teorias não se muda a realidade, mas sem elas também não há mudança significativa, emancipatória. Pode haver deslocamentos, mais do mesmo, em outro lugar. (GOHN, 2008, p. 40).

Este estudo responde a duas indagações. Interroga como se articulou o binômio "educação e desenvolvimento" ${ }^{1}$, a partir da produção da Sociologia Política da Educação, que influenciou a formação dos profissionais e pesquisadores no Brasil. $\mathrm{E}$ analisa as relações estabelecidas entre planejamento (como ação de distribuição de recursos e poderes) e a regulação do sistema educacional brasileiro. Para isso, a pesquisa mapeou as formas de cognição mediadoras de procedimentos orientadores da ação, com os quais diferentes atores interagem. Tem por objetivo argumentar que as mudanças do modus operandi de planejamento educacional no País são efeitos de novas relaçóes entre governantes e governados dos últimos 30 anos. Em especial, da participaçấo deliberativa de atores não governamentais.

A apreensão dos paradigmas orientadores da ação de atores governamentais e não governamentais, relevantes na gestão do sistema educacional brasileiro entre eles, citamos a Undime, Consed, CNTE, Anped, "Todos pela Educação" - permite identificar alternativas de planejamento em construção. E entre elas, indagar quais, paulatinamente, vêm adquirindo maior protagonismo na formulação e implementação das políticas públicas na área educacional. Nos fóruns de representação atuantes no sistema educacional brasileiro, a influência dessas entidades não se faz, apenas, como ação concertada e uniforme na defesa de interesses legítimos, mas como portadores de práticas discursivas desiguais e em conflito. Esses atores interagem mediados por compreensóes diversas da articulação entre educação e desenvolvimento na estruturação e no funcionamento do sistema educacional, e formulam instrumentos políticos para agir sobre ele.

Cunha (1981b, p. 6) já destacava: "apesar dos padrôes verticalistas e centralistas, é possível assinalar a participação dos educadores na elaboração da política educacional do Estado, configurando um movimento de baixo para cima e da periferia para o núcleo". As conferências de educaçáo (ou de 
educadores) foram arranjos institucionais que propiciaram essa participação. $\mathrm{Na}$ atualidade, os movimentos de ação política "de baixo para cima" têm crescentemente participado na formulação da agenda política em educação. A realização da Conferência Nacional de Educaçáo - CONAE - em 2010 reuniu, aproximadamente, 5.000 educadores, representantes das mais diferentes regiōes do Brasil e foi coordenada pelo Ministério da Educação. Seu documento final apresenta proposiçóes para a elaboraçáo de Lei contendo o Plano Nacional de Educação, que deverá estabelecer a política de Estado para a área da educação escolar no País.

A atuação de representantes de diversos movimentos sociais no aparelho do Estado, a atuação de organizaçóes internacionais as mais diversas na área da educação e a intervenção de entidades empresariais na agenda educacional impóem ao analista social, além do estudo referente às demandas ascendentes, o reconhecimento de açôes assimptóticas. Ou seja, daquelas ações que provocam proposições em tensão com as concepçôes hegemônicas em um dado período. Quais os fundamentos político-sociológicos implícitos nas proposições mais atuais sobre educação e desenvolvimento? Como essas proposiçôes incorporaram as reflexôes anteriores? Para responder essas indagaçôes, este estudo pressupôs o esgarçamento das fronteiras, exacerbadas nos períodos ditatoriais, entre a sociedade civil e o Estado. Desse modo, reconhece que o termo "políticas públicas" se refere aos resultados das açóes coordenadas e articuladas entre atores governamentais e não governamentais, ou seja, tem por referente uma sociologia da ação pública (LASCOUMES; LE GALÉS, 2007). Nesse referente, o processo de construção de novas agendas, as questōes que as configuram ou os temas ignorados são expressão de modos de interaçáo desigual entre atores sociais diversos, como modos de regulação social ${ }^{3}$.

\section{Educação e desenvolvimento: planejamento da ação estatal para a modernização do País}

Educação e Sociedade é uma antologia clássica e presente na formação de inúmeros educadores e sociólogos da Educaçáo. Essa obra, organizada por Pereira e Foracchi (1971) debate, ainda presente, em relaçáo ao binômio "educação e desenvolvimento". Cinco artigos, que compóem a última parte desse compêndio, abordam o tema em países ditos à época "subdesenvolvidos". Sociólogos cuja formação 
foi fortemente influenciada por Florestan Fernandes, Luiz Pereira e Marialice Foracchi, organizadores da coletânea, selecionaram artigos, cuja sequência é expressiva da articulação estabelecida entre os termos.

$\mathrm{Na}$ antologia, o primeiro termo - desenvolvimento - foi significado por três economistas (MYRDAL, 1960, FURTADO, 1962, URQUIDI; 1973) e precedem as intervençóes de Anísio Teixeira e Florestan Fernandes, pesquisadores da educaçáo brasileira e expoentes no campo educacional do pensamento das matrizes liberal e socialista, respectivamente.

No primeiro artigo, Myrdal (1973) introduz o leitor na ideia que o desenvolvimento de um país importaria na ruptura com círculos viciosos de causação da pobreza, mediante intervenção governamental corretiva. Em seus trabalhos sobre economia do desenvolvimento, Myrdal alertava que esta relação nas nações ricas e nas naçóes pobres podem jamais convergir. Ao contrário, podem divergir, com os países pobres confinados à produção dos bens primários de menor valor agregado, enquanto os países ricos continuam a usufruir dos lucros associados à economia de escala. Por essa razão, há a necessidade de intervenção corretiva do Estado pela via do planejamento.

A contribuição mais conhecida de Gunnar Myrdal para o desenvolvimento/subdesenvolvimento está no princípio do círculo vicioso, que ele denomina "causação circular e acumulativa", pelo qual "um fator negativo é, simultaneamente, causa e efeito de outros fatores negativos". Myrdal cita com propósito explicativo a Bíblia (São Matheus, XXV: 29, Cf. XIII): "A quem tem será dado e terá abundância, mas de quem não tem será tomado mesmo o que não tem". Em última instância, os países ricos reproduzem a riqueza e os pobres reproduzem a pobreza. (MACHADO, 1999, p. 205).

Essa concepção vai fundamentar o argumento delineado no início do artigo de Florestan Fernandes sobre o dilema educacional brasileiro:

Enquanto as condiçóes internas se agravaram pela atividade contínua e irrefreada dos mecanismos socioeconômicos que provocam, nos países de estrutura econômica dependente, devastação com empobrecimento econômico-demográfico de áreas férteis e expansão 
desordenada de centros circunstancialmente ativos de produção, novas exigências histórico-sociais alargaram as funçôes da educação sistemática [...]. (FERNANDES, 1973).

Para Myrdal (MACHADO, 1999), as condiçôes estruturantes do desenvolvimento capitalista em países subdesenvolvidos promovem desigualdades econômicas e regionais, e Florestan Fernandes reitera a mesma perspectiva ao destacar ser coetânea e interligada, nos países de estrutura econômica dependente, a existência de áreas devastadas e centros ativos. No artigo que compóe a coletânea (FERNANDES, 1973), o sociólogo brasileiro questiona a concepção de subdesenvolvimento como uma etapa de um processo e o considera como resultante de relaçóes assimétricas, pressuposto essencial para um planejamento no qual a educação possa contribuir para o desenvolvimento.

A obra de Celso Furtado constituiu para o Brasil uma das referências maiores para o planejamento de políticas econômicas e sociais articuladas na direção da superação de uma situação de subdesenvolvimento. $\mathrm{O}$ artigo constante na coletânea pertence a uma primeira fase de sua obra na qual o economista aponta a função da teoria econômica que, segundo ele, "só se justifica quando nos arma para conhecer e explicar a realidade" (SZMRECSÁNYI, 2001, p. 348).

Nesse período uma das ideias pioneiras de Furtado foi a da equiparaçáo do desenvolvimento ao aumento da produtividade física média do fator trabalho, resultante de mudanças na forma e nas proporçóes da sua combinação com os demais fatores de produção - vale dizer, do progresso técnico dentro de determinada dotaçáo de fatores ou recursos. Outra era a da importância da distribuição da renda na indução dessas mudanças mediante o crescimento e a diversificaçáo da procura de um lado, e a acumulação e as inversôes de capital do outro. E uma terceira foi a das tendências ao desequilíbrio externo e à inflação provocada por tal crescimento nos países em desenvolvimento - tendências que só podem vir a ser superadas pelo aumento das exportaçóes e/ou pela substituição de importaçôes, meios que não são espontaneamente alcançáveis por intermédio do livre 
jogo das forças de mercado, exigindo em consequência a adoção de medidas de controle governamentais. (SZMRECSÁNYI, 2001, p. 348).

Sob esses pressupostos, o economista cepalino apontava a importância da ação coordenada (mediante planejamento) sobre os elementos dinâmicos do sistema econômico na implementação de políticas anticíclicas. Para Furtado (SZMRECSÁNYI, 2001), a geração de demanda agregada e medidas anticíclicas eram atribuições do Estado e fatores de desenvolvimento e, nesse processo, caberiam mudanças planejadas do sistema educacional, como parte de estratégias sociopolíticas para o desenvolvimento. No artigo constante na coletânea, Furtado (1962), ao destacar a tomada de consciência da situação de subdesenvolvimento, conclama à ação conjugada de especialistas dos diversos ramos das Ciências Sociais no sentido de reformular as funçóes do Estado. Para o economista brasileiro, o planejamento econômico e social é inevitável nos países subdesenvolvidos e destina-se a criar as condiçóes de desenvolvimento capitalista, por sua vez, condição do bem-estar social.

Urquidi (1973), no terceiro artigo sobre desenvolvimento, distinguiu para a América Latina o desenvolvimento econômico e o avanço social, e caberia aos economistas estabelecer requisitos sociais para a consecução do primeiro. Neste artigo, o binômio é articulado pela apreensáo dos aspectos sociais do desenvolvimento econômico e, ao formular crítica à Sociologia, Urquidi (1973) propôs que esta se responsabilizasse por identificar os obstáculos e consequências sociais do crescimento econômico:

O economista não teria dificuldade em assinalar os requisitos sociais do mesmo [desenvolvimento econômico] e esperaria do sociólogo e de seus congêneres profissionais que, de um lado, indicassem como vencer os obstáculos sociais e institucionais ao crescimento e, de outro, estimassem as consequências sociais de determinadas soluçôes e apresentassem dados e argumentos que permitissem, quando em face de mais de uma possibilidade, optar por uma solução ou por outra com plena consciência dos resultados econômicos. (URQUIDI, 1973, p. 378). 
O estudo de Urquidi (1973) introduz a concepção de planejamento integrado entre as dimensóes econômicas e sociais, a nosso ver com predomínio da primeira dimensão. Nos artigos dos três economistas, o desenvolvimento do capitalismo em países subdesenvolvidos acha-se em causa. Mas esse só se faria mediante a intervenção racional, preferencialmente estatal, cujo eixo de ação encontra-se na atuação conjugada e coordenada de especialistas nas diversas áreas de conhecimento.

O uso do termo "país subdesenvolvido" importava no reconhecimento em uma mesma formação social da existência dual de um setor moderno - urbano industrial - e um setor atrasado - rural, oligárquico, de economia tradicional. Entretanto, é a relação simbiótica entre desenvolvimento e subdesenvolvimento, moderno e atraso, que importava destacar, superando acepçōes defensoras de processos lineares e/ou por estágios. Esses são temas recorrentes no paradigma do nacional-desenvolvimentismo estatalmente orientado. $\mathrm{O}$ desenvolvimento não se fazia na mesma dimensão e intensidade por todos os países, se internamente coexistem de modo articulado regiōes com elevados padrões socioeducacionais e outras subdesenvolvidas, isso é visto como processo de crescimento e diversificação econômica, que requeria ação estratégica. A intervenção corretiva do Estado, pela via do planejamento, era o caminho possível para superação dessa situação.

O desenvolvimento importava em crescimento da economia nacional e em mudanças no sistema educacional, para que este se adaptasse a uma nova realidade. Nessas perspectivas, esse subsistema social deveria cumprir funções derivadas das necessidades econômicas, políticas ou sociais do desenvolvimento, pela massiva e abrangente socialização dos indivíduos e sua possível alocação meritocrática ou estruturalmente orientada 5 .

A análise desses autores pressupóe, ainda, a localização dos interesses e dos interessados na manutenção de estruturas sociais iníquas e atrasadas - o que está presente no debate político do período. Pretendia-se atingir as causas socioeconômicas provocadoras do subdesenvolvimento mediante a ação de um Estado e de sua burocracia, vistos como capazes de atacar essas estruturas. Permanece nesses autores, como estratégia política implícita, aquela destacada por Domingues (1999), ao afirmar que o Estado - e, acrescentamos, sua burocracia - aparece como o agente - a "subjetividade coletiva" - fundamental para deslanchar o processo de desenvolvimento. 
Desenvolvimento seria, então, uma forma particular de modernização, caracterizada por uma mudança profunda das estruturas produtivas do país, de sua estrutura de classes, e pela democratização política e social, com a incorporação das massas à nação, acompanhada de transformaçóes no próprio cenário internacional da dependência brasileira. (DOMINGUES, 1999, p. 84).

Para esse desenvolvimento, importaria atribuir ao Estado uma função protagonista da ação política, pela via do planejamento. Nessa tradiçấo sociológica, o desenvolvimento da sociedade brasileira é mediado pela ação intencional e articulada do Estado - a via do planejamento -, ator capaz de mobilizar a sociedade para a produção de mudanças mais profundas no País. Tratava-se, também, de conferir ao planejamento estatal um caráter científico e sistemático.

Ao mesmo tempo que os educadores lutavam pela reconstrução educacional do país julgando que faziam planejamento da educação, o Brasil entrava, lentamente e por etapas, na sistemática de planejamento setorial e global [...] Aparece assim, pela primeira vez [Programa de Metas, do governo Juscelino Kubitschek], a afirmação da vinculação educaçáo-desenvolvimento, sendo a educação considerada apenas na sua função de formadora dos quadros técnicos exigidos pelo crescimento econômico. (HORTA, 1997, p. 159)

No compêndio organizado por Pereira e Foracchi (1973), a marca deixada nos artigos dos economistas inscreve o paradigma de que o processo de desenvolvimento é decorrência de intervençôes sobre condiçôes estruturais mais amplas, reguladas pela açáo do Estado, sujeito capaz de propiciar essas novas condiçóes. Para Pereira (1967), houve uma tendência à sociologização do pensamento educacional brasileiro durante a década de 50 do século XX. Buscavase, de acordo com o sociólogo da Educaçáo, a partir desse período, compreender a interdependência entre a educaçáo escolar e a dinâmica das estruturas sociais e, a partir desta compreensão, promover um processo de intervenção racional na realidade, destinado à aceleração do ritmo das transformaçóes estruturais concebidas como positivas ao nível da consciência social. 
Horta (1982) destaca para o período de 1956-1960 o surgimento de toda uma teorização em torno das relaçôes entre educação e desenvolvimento. Esta teorização ia desde afirmações que o desenvolvimento econômico deveria ser buscado primeiro, pois traria como consequência necessária o desenvolvimento educacional, até a afirmação contrária de que a educação era pré-condição essencial para o desenvolvimento econômico. Entre os extremos, uma gama de posiçôes diferenciadas, desde os que destacavam a necessidade de um planejamento integral da Educação ${ }^{6}$, articulado com o planejamento econômico e social global, até o "planejamento dos educadores", entendido como a elaboração de normas para distribuição dos recursos públicos destinados à educação.

Essa contraposição entre planejamento integral e planejamento dos educadores, exposta por Horta (1982), consiste em chave de leitura do binômico Educação e Desenvolvimento, presente desde os anos 1950/1960 do século XX. Para a primeira perspectiva, o planejamento educacional como função derivada ou articulado às necessidades do desenvolvimento econômico e social. Para a segunda, "planejamento dos educadores", a formulação técnica das necessidades de universalização da prestação de serviços que asseguram o direito à educação. Nos argumentos de Teixeira (1957) e Fernandes (1960), expostos no compêndio organizado por Pereira e Foracchi (1973), configuram-se essas duas posiçóes fundantes do pensamento sociopolítico em educação.

\section{Anísio Teixeira e o planejamento dos educadores}

$\mathrm{O}$ artigo do educador Anísio Teixeira ${ }^{7}$, na coletânea, traz um rigoroso diagnóstico do sistema educacional do período com o objetivo de "ajustá-lo às exigências do desenvolvimento brasileiro", o qual se orientava no sentido do crescimento urbano-industrial. Em especial, Teixeira (1957) destacava a necessidade de enfrentamento da configuração institucional sistêmica "mais à maneira de um obelisco" do que mesmo de uma pirâmide. E o diagnóstico por ele elaborado persiste como questáo ainda náo resolvida para a atualidade:

A expansão educacional obedece à tendência de alargar as oportunidades de educação seletiva para a classe média e a superior e à de custeá-la com recursos públicos subtraídos à educação popular e à educação de formação para o trabalho produtivo. As duas tendências são sobrevivências 
do modesto sistema educacional de antes de 30, destinado a uma sociedade em estado de relativa estagnação, com reduzidíssima classe média e também pequena classe superior. [...] Façamos de nosso sistema escolar um sistema de formação do homem para os diferentes níveis da vida social. (TEIXEIRA, 1957, p. 411).

Herdeiro e divulgador da tradição liberal mais igualitária no Brasil ${ }^{8}$, na vertente do escolanovismo, a obra de Anísio Teixeira expressou um projeto político institucional para a educação escolar do País, com a singularidade de propor a articulação do papel protagonista do Estado e a participaçáo da sociedade civil ${ }^{9}$ na administraçáo educacional. No final da década de 1950, seu artigo fundamentava como exigência de desenvolvimento uma educação primária comum e para todos - de massas -, capaz de superar a escola seletiva, propedêutica e elitista, vista como disfuncional à nova realidade social que emergia.

A articulação da educação escolar com as mudanças sociais em curso no período dar-se-ia, de acordo com Anísio Teixeira, pela via da função estabilizadora da escola. Ou seja, mediante uma formação básica comum, capaz de forjar indivíduos necessários às classes sociais, pela posterior seleção meritocrática. Sob esses fundamentos, o pensamento liberal de Anísio Teixeira (1973) considerava que, ao se expandir o sistema popular de educação compreendendo o ensino primário e o técnico, este se articularia também às exigências do desenvolvimento econômico e social. Para Teixeira $(1957,1968)$, um sistema público de educação asseguraria uma base comum de aprendizagem a cada um e a todos os indivíduos cidadãos, a partir da qual, mediante vocaçóes e interesses, trajetórias diversas de escolarização seriam possíveis.

Fortemente combatido pela rede privada confessional no período ${ }^{10}$, o diagnóstico anisiano opera no sentido de formular proposiçóes capazes de alterar as políticas de financiamento, de organização das escolas e do sistema educacional no País para atingir o objetivo de assegurar o direito comum:

[...] a reorientação da escola para que a mesma se faça uma escola de trabalho e de preparação real e não apenas de atividades rituais para o diploma, e a redistribuição de recursos para a educação, estabelecendo-se a prioridade da gratuidade do ensino popular universal e o custeio do 
ensino pós-primário e superior em parte com recursos públicos e, em parte com recursos do estudante, salvo se lhe não assistirem condiçôes para tal e houver obtido a matrícula em concurso público feito em escolas oficiais. (TEIXEIRA, 1957, p. 411-412).

Para o educador, somente o Estado, com os seus recursos e meios de ação, poderia levar a termo o empreendimento de organização dos serviços que assegurariam o direito de todos. E no artigo do final da década de 1950, constante na coletânea, defendia uma organização escolar sob padróes previamente fixados, como condição necessária para a superação da elevada e precoce seletividade existente no sistema educacional brasileiro, de sua desigualdade sistêmica e, especialmente, de sua desfuncionalidade às exigências do desenvolvimento urbano industrial ${ }^{11}$.

Anísio Teixeira (1968), posteriormente, explicitou a distinção que percorre sua obra e a contrapóe ao ideário do Estado autoritário. Para este, o desenvolvimento econômico requeria a formaçáo técnica de mão de obra, mediante o arranjo corporativo. Para o educador liberal, o desenvolvimento da educação básica e comum é um bem em si, se estiver ao alcance de todos, mediante a aquisiçáo de conhecimentos e aperfeiçoamento pessoal. Sua obra política contém, ainda, um segundo ponto de distinção: "[...] a pressão sobre as escolas no sentido de alterar a conduta docente do improviso para o registro sistemático da vida escolar" (NUNES, 2000, p. 348). De acordo com essa autora, a síntese da intervenção política de Anísio Teixeira foi ordenadora e recriadora do espaço escolar urbano e de criação de um campo de identificação dos educadores profissionais:

Essa pedagogia urbana foi tecida por uma rede de saberes e poderes articulados que exigiram a emergência de grupos especializados dotados de uma consciência ordenadora e de uma capacidade de ideologização capaz de lidar com novos conhecimentos em favor de uma política educativa desdobrada no cotidiano da cidade. (NUNES, 2000, p. 585).

Em Anísio Teixeira, o planejamento das instituições educacionais que organizariam a educação escolar no País se projetava em dois vetores. Um primeiro, a universalização de serviços que asseguram direitos, e o segundo, 
a primazia da ação técnica e procedimental para o funcionamento das instituiçōes educacionais. Nesse segundo vetor, a observância de critérios técnicos e prescritivos para o funcionamento dos sistemas educacionais achavase assinalada na obra do educador, e dessa forma o desenvolvimento de um sistema nacional de matriz burocrático-profissional ${ }^{12}$, porém descentralizado e com maior autonomia dos atores locais.

Em síntese, a obra de Anísio Teixeira, ao articular educação e desenvolvimento, expunha a defesa de uma regulação conjunta entre Estado e profissionais da educação, um arranjo institucional que buscava combinar um componente normativo a cargo do Estado com a atuação de profissionais, em detrimento das concepçôes acerca de missão e vocação, de cunho mais assistencialista. Ou seja, a articulação do binômico "educação e desenvolvimento", no projeto político desse educador, tinha por objetivo a construção e disseminaçáo pelo País de um sistema de prestação comum de serviços educacionais, formado por profissionais em atuação nas suas unidades. O planejamento do sistema educacional, com normas e organizaçáo de meios de modo racional e uniforme, aliadas à atuaçáo de profissionais da educação capazes, possibilitaria, nos termos de Anísio Teixeira, um arranjo das instituiçôes educacionais coetâneo com as necessidades do desenvolvimento.

Outra chave de leitura crítica do artigo e da obra de Anísio Teixeira foi elaborada por Pereira e Foracchi (1973). Para esses autores, Anísio, após um rigoroso diagnóstico da situação educacional, formularia suas funçôes ideais com o objetivo de ajustar a educação escolar às imposiçôes do desenvolvimento. Consideram que o educador liberal ofereceu um ideário pedagógico, sob o suposto que alterações no sistema educacional desencadeariam forças propulsoras do desenvolvimento urbano industrial. A crítica exposta por Pereira e Foracchi (197) fundamentava-se na primazia das determinações do desenvolvimento econômico sobre a atuação das instituições educacionais.

Por sua vez, as contribuições do neoinstitucionalismo histórico (SOUZA, 2003) indagam como as instituiçóes políticas - sistemas educacionais inclusos - orientam a formulação e implementação de políticas públicas. O pressuposto subjacente considera que instituiçóes preexistentes tornam o curso de certas políticas públicas mais fáceis que de outras, redefinem as alternativas e mudam a posição relativa dos atores. Nesse sentido, está a aposta política do pensamento liberal mais igualitário no Brasil em planejar mudanças no interior do sistema 
educacional brasileiro, como condição e articulado ao desenvolvimento econômico capitalista, porém mais igualitário.

\section{Florestan Fernandes: planejar qual desenvolvimento?}

O compêndio organizado por Pereira e Foracchi (1973) encerra sua "Parte VI - Educação e Desenvolvimento" com artigo de Florestan Fernandes $(1960)^{13}$. Neste, o sociólogo, ao apontar o desenvolvimento simultâneo de um capitalismo dependente, do sistema de classes e do regime democrático, os articula com mudanças necessárias à educação sistemática. A articulação entre educação e desenvolvimento recebeu tratamento singular no conjunto da obra de Florestan Fernandes e o artigo divulgado na antologia a partir de 1964 inicia a difusão de sua reflexão:

Nos seus termos, apesar de a "transplantação da civilização ocidental para a zona tropical” constituirse "em processo penoso, cheio de dificuldades e de transtornos”, era viável a construçáo da civilização moderna no país, caso certos requisitos como o da expansão da educação e o da intervenção racional das ciências sociais fossem realizados. [...] Nos dois campos, Florestan atuou ativamente, articulando sua capacidade de açáo em prol da democratizaçáo do acesso ao ensino em todos os níveis, exprimindo o compromisso selado com sua origem popular. Ele próprio havia sido fruto das oportunidades ampliadas no campo educacional e da criação da Universidade de Sáo Paulo, para cujo concurso os renovadores da educação foram decisivos, como o foi Fernando de Azevedo, que o convidou para ser seu assistente em 1944. (ARRUDA, 2010, p. 13).

No início da década de 1960, Florestan Fernandes (1973), em artigo de forte inspiração manheimiana, advogará os lugares dos cientistas sociais no planejamento sistêmico e a funçáo destes para o enfrentamento do que também denominará dilema educacional brasileiro:

[...] [a] incapacidade de ajustar as instituiçóes educacionais às diferentes funçôes psicoculturais e socioeconômicas, 
que elas devem preencher e de criar um sistema educacional suficientemente diferenciado e plástico para corresponder, ordenadamente, à variedade, ao volume e ao rápido incremento das necessidades escolares do país como um todo" pressupóem mudanças sociais orientadas pelo planejamento, capaz de superar as funçóes estáticas universais da educação sistemática (FERNANDES, 1960, p. 412).

Para Florestan Fernandes (1973) caberia aos cientistas sociais o estudo do dilema educacional, à luz das características estruturais próprias do capitalismo dependente, com o objetivo de propor práticas capazes de exercer influências secularizadoras e racionalizadoras. Se a questão de pesquisa formulada à obra de Florestan Fernandes, em especial ao artigo de 1960, indaga sobre a articulação do binômio, é necessário situar a perspectiva do sociólogo quanto ao conceito de desenvolvimento do subdesenvolvimento.

Para Cardoso (2005), a crítica central posta pela análise política de Florestan dirige-se ao conceito de capitalismo dependente, como expressão de uma forma nova do desenvolvimento capitalista, e à apreensão da noção de subdesenvolvimento, como espaço e tempo de expansão do capital. De acordo com Florestan (1960), a situação denominada de "subdesenvolvimento" decorria da relaçáo heteronômica do desenvolvimento capitalista subordinado, no qual a presença da pobreza extrema e de privaçôes materiais decorre, não do possível fracasso das políticas estatais de proporcionar níveis de vida aceitáveis, mas da integração sistêmica e do desenvolvimento do capital pelo mundo. Em outras palavras, para Florestan Fernandes subdesenvolvimento não constitui uma etapa do desenvolvimento capitalista, e sim o seu produto.

Enquanto as condiçóes internas se agravaram pela atividade contínua e irrefreada dos mecanismos socioeconômicos que provocam, nos países de estrutura econômica dependente, devastação com empobrecimento econômico-demográfico de áreas férteis e expansão desordenada de centros circunstancialmente ativos de produção, novas exigências histórico-sociais alargaram as funçôes da educaçâo sistemática [...]. (FERNANDES, 1960, p. 414). 
É sob essa perspectiva que o artigo de 1960 expōe preocupações sobre a necessidade da profissionalização sociológica no tratamento da situação educacional do País. Para Florestan, o dilema institucional da educação brasileira sofreria, mediante açóes de sociólogos, controle racional - intervenção deliberada na realidade - capaz de contribuir para mudanças sociais orientadas da sociedade. Os cientistas sociais poderiam alargar os horizontes tanto dos educadores $^{14}$, dos leigos letrados e introduzir novos critérios de avaliação da situação educacional brasileira. Em seu artigo, afirmava que, mediante o planejamento, as Ciências Sociais possibilitariam mudanças, ao associar a via da intervenção cientificamente controlada à da análise sociológica sobre as estruturas condicionadoras da especificidade brasileira. Para o sociólogo da Educaçáo, seria viável a construção da civilização moderna no País, caso certos requisitos como o da expansão da educaçáo e o da intervenção racional das ciências sociais fossem realizados.

[De acordo com Florestan Fernandes] Os especialistas teriam condições de mobilizar os resultados das pesquisas para alterar sistemas de relaçóes, por meio de novas descobertas forjadas no embate com as questóes sociais. No campo da sociologia, o especialista seria a figura do profissional da corporação científica, um observador dos fenômenos sociais, capaz de formular regras de explicação e de propor medidas de correção. (ARRUDA, 2010, p. 13).

Nesse sentido, a crítica de Florestan ao "plano" dos educadores fundamenta-se na não-apreensão das condicionalidades sociais impostas pelo desenvolvimento heteronômico, capaz de articular modernização e tradição, que por sua vez interagiam fortalecendo-se mutuamente. Entretanto, o diagnóstico da herança institucional, que não se ajusta às novas necessidades do desenvolvimento [capitalista], aproxima a análise de Florestan Fernandes à de Anísio Teixeira sobre o sistema educacional brasileiro. A esses autores, é comum o reconhecimento das inadequações sistêmicas da educação às exigências do desenvolvimento do capitalismo no Brasil:

Nas áreas em que a produtividade assegura crescimento demográfico contínuo, expansão da agricultura e prosperidade de núcleos urbanos regionais, as instituiçóes 
escolares não contribuem para facilitar o ajustamento de segmentos flutuantes da populaçáo para educar o "homem do campo" nem para formar o homem da cidade. Nas áreas em que as tensóes étnicas poderiam ser aliviadas ou removidas, mediante intervençóes irradiadas a partir da escola, esta permanece insensível aos problemas humanos que se desenrolam em seu próprio nicho. Nas áreas em que a urbanização e a industrialização atingem certa intensidade, as várias camadas da população, incluindo-se entre elas os "nativos" e os "adventícios", não acham, nas escolas, a necessária preparação para o estilo urbano de vida, com suas variadas exigências na diferenciação do ensino especializado. (FERNANDES, 1960, p. 417-418).

Para o sociólogo brasileiro, o dilema a ser enfrentado é, também, de fundo institucional, diríamos sistêmico, e vai requerer da Sociologia a conjugaçáo de motivos empíricos, práticos e teóricos. Com outras palavras, para Florestan Fernandes a profissionalização no tratamento das questôes educacionais e sociais é compatível com um compromisso dos sociólogos com o desenvolvimento do País. Entretanto, a noção de desenvolvimento em Florestan envolve uma perspectiva que o diferencia.

O artigo original completo, divulgado em 1958, articula de modo explicito as noções de "ciência aplicada" e "educação" com a de "mudança social provocada", esta última apreendida como "[...] capacidade dos agentes humanos na escolha de fins alternativos ou exclusivos e de pô-los em prática através de meios que assegurem, no mínimo, controle racional do desencadeamento e das principais fases do processo" (FERNANDES, 1966, p. 171). É mediante essa articulação, de inspiração manheimiana, que Florestan introduz o planejamento do desenvolvimento e o lugar da educação na construção da modernidade. Em Florestan Fernandes, o planejamento da educação faz-se, para usar os termos de Horta (1997), como planejamento integral do desenvolvimento; este, por sua vez, é resultante da situação de relaçóes heteronômicas.

A solução aventada em Florestan Fernandes, construção de alternativas pela via do planejamento sistemático, considerada no artigo de 1960 como mudança cultural provocada, articula as Ciências Sociais - capazes de estimular maior racionalidade, secularizaçáo e tratamento profissional - à educaçáo, 
sistema responsável mediante a transmissão e socialização do complexo acervo de conhecimentos necessários como fatores de reconstrução social. Influenciada, também, pela chamada Teoria do Desenvolvimento Econômico de matriz keynesiana, a via do planejamento apresenta-se no contexto do nacionaldesenvolvimentismo como forma de integração sistêmica entre economia, sociedade e educação, na qual esta última era apreendida como função derivada do desenvolvimento econômico. Antecipando-se à vertente tecnocrática da ditadura militar, o período de 1955-1960 no Brasil - governo Kubitschek - difunde o princípio político das exigências postas à educação pelo desenvolvimento. Entre elas, a mudança cultural provocada, decorrente da apreensão científica (das condiçóes estruturantes) que obstaculizam o desenvolvimento.

\section{Educação e desenvolvimento social: reprodução das estruturas socioeconômicas}

É especialmente no período da ditadura militar que o nacionaldesenvolvimentismo expressou toda sua pujança e viés autoritário. E, neste período, a obra de Cunha ${ }^{15}$ (1975) constituiu, de acordo com Cury (1981), um dos principais referentes na formação da Sociologia Política da educação brasileira e de crítica às concepções mais economicistas da articulação entre desenvolvimento e educação. No período militar, a articulação do binômio envolvia a integraçáo dos desenvolvimentos - educacional, social, econômico -, e a função estratégica do sistema de educação escolar nessas mudanças envolvia a superação das desigualdades pela formaçáo individual do capital humano.

Cunha (1975), por sua vez, argumentava contra a suposição corrente do período de que a educação permitiria aos indivíduos, portadores de qualidade/quantidade de conhecimentos, seja qual fosse sua extraçáo social de origem, ascenderem socialmente de acordo com seu mérito individual. Para o autor, a educação escolar desempenharia a função ideológica de dissimular os mecanismos de discriminação da própria educação, bem como os da ordem econômica. Devido a rigorosa argumentaçáo presente nessa obra, sua apropriação discursiva se fez com a difusão de três topoi da atualidade. A apreensão do pensamento liberal como ideologia, a função de reprodução das desigualdades sociais do sistema educacional e a análise da política educacional como ação do Estado, visto como "[...] agência de concentraçáo do capital na nova fase de desenvolvimento da economia brasileira"16 (CUNHA, 1975) 
Esses pressupostos constituíram e constituem os alicerces de inúmeros estudos posteriores das políticas e do sistema educacional, vistos como fatores de "reprodução da ordem social". Por essa razão, importa reter três concepçôes fundamentais sobre o binômio "educação e desenvolvimento", presentes nas Ciências Sociais do período nacional-desenvolvimentista e sistematizadas por Cunha $(1975$, p. 21).

Educaçáo como fator de crescimento de renda como legitimador do investimento em capital humano;

Educação como fator de mudança social e modernização societária, às quais se acrescenta, apreendidas como urbanização e industrialização e vetor de superação do subdesenvolvimento e a escolarizaçáo processo de formaçấo de indivíduos empreendedores;

Educação como fator de construçấo de uma sociedade mais justa e desse modo de desenvolvimento social. ${ }^{17}$

A crítica empreendida por Cunha (1975) às funções da educação como fator de desenvolvimento social tinha por alvo principal as vertentes autoritárias do ideário do nacional-desenvolvimentismo, no qual o crescimento econômico planejado era visto como capaz de resolver per si problemas como desigualdade excludente e marginalização. Mas o autor dirigia-se também às concepçôes consideradas como mais ingênuas - liberais - que atribuiriam um papel redentor à educação escolar. A educação era tratada pelo Estado autoritário, no Brasil, como a luz capaz de iluminar toda uma imensa "regiáo" da vida social deixada à sombra pelo desenvolvimento econômico. É como se o desenvolvimento "econômico" não tivesse as repercussóes sociais esperadas como seu resultado automático (CUNHA, 1975).

Desse modo, a obra de Cunha (1975) tinha por motivação política a desconstrução da ideologia do nacional-desenvolvimentismo e é portadora de lógicas de ação coletiva ${ }^{18}$ das realizaçôes históricas em construção, que produziriam a superação do período ditatorial. Em uma época na qual governos e Estado se achavam imbricados, este último era visto como o inimigo a ser combatido pela "sociedade civil", mediante a correta consciência de seus problemas e soluçóes. Para Cunha (1975), desenvolvimento social e, consequentemente, educacional importariam na mudança profunda das estruturas produtivas do País, de sua estrutura de classes. 
A resposta formulada por Cunha (1981a) às críticas apresentadas por Cury (1981) é esclarecedora da relação que estabelecia entre educação e o termo que sua obra difundiu, "desenvolvimento social". Tratava-se de demonstrar as repercussões "sociais" esperadas daquele desenvolvimento econômico e combater a possibilidade de medidas destinadas a compensar os insuficientes resultados desse desenvolvimento. Esse referente analítico subordina o planejamento educacional e, de modo consequente, o desenvolvimento às lutas sociais produtoras de transformaçóes.

Como reconhece Cunha (1981a), uma das vertentes de gênese de sua obra acha-se em Ianni (1977). Nesta, o sociólogo sintetiza duas concepçóes de desenvolvimento presentes até o período da ditadura militar:

A história da política econômica governamental brasileira, desde 1930, indica que esta oscilou entre duas tendências principais. Uma dessas tendências, que pode ser denominada estratégia de desenvolvimento nacionalista, [...] continha, como pressuposto implícito e explícito, o projeto de um capitalismo nacional, como única alternativa para o desenvolvimento econômico e social. [...] A outra, que pode ser chamada estratégia do desenvolvimento dependente [...] continha [...] o reconhecimento das conveniências e exigências de interdependência das naçôes capitalistas, sob a hegemonia dos Estados Unidos. [...] O que ocorria, efetivamente, era sempre uma coexistência das duas polarizaçôes como tendências principais. Algumas vezes, entretanto, esse movimento pendular parece ter sido perturbado pela manifestação de uma terceira tendência, que defendiam a participaçáo aberta do Estado nas atividades econômicas. (IANNI, 1977, p. 307-308).

A análise de Ianni (1977) sobre Estado e planejamento no Brasil encerrase após a exposição dessas tendências com o reconhecimento da emergência de uma "tecnoestrutura estatal" e, desse modo, a transição do princípio do clientelismo para o princípio do mérito, que passou a caracterizar o Estado burguês. No contexto autoritário, analisado por Ianni (1977), o horizonte de regulaçáo dos sistemas sociais e de governance dos atores apontava para mudanças no predomínio de lógicas de ação fundadas na troca de favores e no 
patrimonialismo, por uma racionalidade na qual o planejamento e a ciência eram considerados como o instrumento de desenvolvimento e destinavam-se a consolidar relaçôes capitalistas de poder.

A educação como função derivada do desenvolvimento econômico permanece, ainda, como referente das análises efetuadas na perspectiva inaugurada por Cunha (1971) e pela Sociologia crítica no Brasil. Nesse referente, o desenvolvimento social é determinado pela economia, pelas relaçôes estabelecidas entre as classes sociais e os sistemas educacionais reprodutores dessas relações. A difusão no País do paradigma reprodutivista da função sociopolítica do sistema educacional fundamenta-se na apreensão e crítica ao desenvolvimento econômico no Brasil como um empreendimento de autonomização política do capital e padronização das relaçôes sociais sob a forma mercadoria. Para esta vertente, o Estado burocrático-keynesiano, especialmente na forma ditatorial, encarnou um modo eficaz de governaçáo do capital. O desenvolvimento social em Cunha (1971, 1981a), especialmente pela via da educação escolar, era apreendido como impossibilidade sob a forma histórica do desenvolvimento do capitalismo no Brasil.

\section{Educação e desenvolvimento social: equalização do crescimento econômico e dos indicadores sociais}

A realização em 2010 da $1^{a}$ Conferência Nacional de Educaçãa ${ }^{19}$, sob os auspícios do Ministério da Educação - MEC, constituiu um momento de expressáo do pensamento educacional brasileiro contemporâneo e de referência para a formulação de políticas públicas em educação. Proposiçôes hegemônicas na Conferência foram sintetizadas em um documento final, divulgado pelo Ministério da Educação logo após o seu término, com o objetivo de fornecer subsídios para a elaboraçáo de Lei aprovando o Plano Nacional de Educação. Após quase cinquenta anos da publicação de Educação e desenvolvimento (PEREIRA; FORACCHI, 1973) e, aproximadamente, trinta e cinco da divulgação de Educação e desenvolvimento social (CUNHA, 1975), como este binômio se acha articulado no documento síntese da Conae (2010)?

Esse documento, à semelhança dos que lhe serviram de referência, se encontra organizado em seis eixos temáticos, seguidos por diretrizes e estratégias de ação. Por ser fonte importante para o planejamento educacional 
contemporâneo no País, este estudo analisou como nele se articulou o binômio "educação e desenvolvimento" e o modus operandi de planejamento.

Nesse sentido, este Documento Final, resultado da CONAE, contribuirá para a construção de políticas de Estado para a educação nacional, em que, de maneira articulada, níveis (educação básica e superior), etapas e modalidades, em sintonia com os marcos legais e ordenamentos jurídicos (Constituição Federal de 1988, PNE/2001, LDB/1996, dentre outros), expressem a efetivação do direito social à educaçáo, com qualidade para todos. Tal perspectiva implica, ainda, a garantia de interfaces das políticas educacionais com outras políticas sociais, num momento em que o Brasil avança na promoçáo do desenvolvimento com inclusáo social e efetiva sua inserçáo soberana no cenário mundial. (CONAE, 2010, p.12, grifo da autora).

A primeira menção ao termo "desenvolvimento" no documento final da CONAE (BRASIL, 2010) expressa um diagnóstico de reconhecimento de uma conjuntura de superação da dependência - efetiva inserção soberana - e, no horizonte próximo, a promoção de inclusão social. Este último termo é reiterado por mais de 18 vezes ao longo do documento. Indica tanto a promoção de equidade de oportunidades educacionais como a efetivação de um sistema universal de prestação de serviços educacionais ou ainda, de modo mais restrito, a inclusão de indivíduos singulares em etapas ou modalidades específicas de atendimento. O diagnóstico que orienta o documento final da Conferência considera que o desenvolvimento - inserção soberana no cenário mundial - se faz mediante inclusão social.

O documento final da Conferência, ao expressar a possibilidade de um desenvolvimento autônomo e mais igualitário no País, reconhece potencialidades das políticas sociais para cumprir esse desafio. Esse referente se acha explícito nas diretrizes propostas para a formulação do Plano Nacional de Educação (PNE), especialmente ao tratar das relaçôes entre justiça, educação e trabalho.

[...] destacam-se as seguintes diretrizes a serem consideradas, com vistas a um novo PNE como política de Estado: [...] 
iii. estabelecimento de políticas de educação inclusiva visando à superação das desigualdades educacionais vigentes entre as diferentes regióes, contribuindo com o desenvolvimento econômico, social e cultural do País [...]. (CONAE, 2010, p. 36).

No entanto, em uma sociedade marcada por profundas desigualdades sociais, de classe, de gênero, étnico-raciais, geracionais, e de pessoa com deficiência, a garantia de uma educação pautada na justiça social, que considere o mundo do trabalho para além da teoria do capital humano e que reconheça e dialogue com a diversidade ampliando a noção de inclusão e igualdade social, constitui um desafio. (CONAE, 2010, p. 123).

O uso do termo "educação inclusiva" expressa a função sociopolítica atribuída à educação como fator de mudança societária. Entretanto, o sentido atribuído às mudanças acha-se posto no diagnóstico inicial formulado sobre o momento de desenvolvimento vivido pelo Brasil. Em diversos momentos do documento, o termo "desenvolvimento" é qualificado como social, e o objetivo pretendido é de equilibrar desigualdades regionais.

Propiciar condiçóes para que as referidas políticas educacionais, concebidas e efetivadas de forma articulada entre os sistemas de ensino, promovam [...] o desenvolvimento social. [...] Esses pontos da agenda são imprescindíveis para assegurar, com qualidade, a função social da educação e das instituiçóes educativas, ou seja, a educação inclusiva: a diversidade cultural; a gestão democrática e o desenvolvimento social [...]. (CONAE, 2010, p. 13).

É também a expressão de uma visão de ordenamento do território e de desenvolvimento social e econômico, na medida em que a complementação da União é direcionada às regióes nas quais o investimento por estudante é inferior à média nacional. (CONAE, 2010, p. 112).

A tradição do pensamento sociológico que reconhecia a desigualdade como produto do desenvolvimento capitalista e a expansão dos sistemas 
educacionais reprodutora das relações de desigualdade acha-se obliterada nessas afirmativas constantes do documento final. É ao tratar do dever do Estado em assegurar o direito à educação - Eixo 1 - que o documento final da CONAE (2010) expressa com maior clareza o modus operandi de planejamento para articular educação e desenvolvimento.

[...] a construçáo de um sistema nacional de educaçáo requer o redimensionamento da ação dos entes federados, garantindo diretrizes educacionais comuns a serem implementadas em todo o território nacional, tendo como perspectiva a superação das desigualdades regionais. Dessa forma, objetiva-se o desenvolvimento de políticas públicas educacionais nacionais universalizáveis, por meio da regulamentação das atribuiçôes específicas de cada ente federado no regime de colaboração e da educação privada pelos órgáos de Estado (CONAE, 2010, p. 21).

Normas preestabelecidas, voltadas para a prescrição uniforme das atribuições dos entes federados, são requisitos para o desenvolvimento de políticas públicas capazes de superação das desigualdades regionais (entre sistemas de ensino). Nesse sentido, a Conferência Nacional aponta para uma dinâmica de planejamento pela via da uniformizaçáo e regulamentaçáo das açóes, a serem realizadas pelos entes federados em todo o território. Indica, também, a transferência para o âmbito federal de um financiamento subsidiário e regulamentado por resultados educacionais medidos pelo Índice de Desenvolvimento da Educação Básica (IDEB).

A regulamentaçấo do Regime de Colaboraçâo deve explicitar a participação da União na cooperaçấo técnica e, especialmente, na determinação de transferências regulares e contínuas de recursos financeiros às instituiçôes públicas dos Estados, DF e Municípios, priorizando os entes federados com baixos índices de desenvolvimento socioeconômico e educacional, tendo como critérios indicadores o IDH, altas taxas de pobreza, índice de fragilidade educacional na oferta de EJA [...]. (CONAE, 2010, p. 23). 
Subjaz ao documento final um projeto político para a educação brasileira, no qual proposições de redimensionamento da "autonomia política" de ação dos entes federados no campo educacional, em torno de normas comuns expressas no Plano Nacional de Educação -, seriam capazes de orientar políticas públicas universalizáveis no território. Diagnóstico subjacente e complementar é que permanecem as desigualdades sociais e regionais devido à fragilidade e fragmentação da ação do poder público central pari passu a um momento no qual ocorre desenvolvimento com inclusão social e inserção soberana. São secundarizadas no documento orientaçóes relativas às políticas regulatórias ou constitutivas, o que indica ao analista uma orientaçáo no sentido da regulação de matriz burocrático do sistema educacional.

Um segundo eixo de articulação do binômio "educação e desenvolvimento" encontram-se nas proposiçóes relativas ao desenvolvimento institucional do sistema. Neste eixo, encontra-se o uso de expressóes como "projeto político pedagógico" e "desenvolvimento da instituição educativa", aliadas a diversas proposiçóes consideradas necessárias à configuração da res publica no campo educacional e de sua gestáo democrática.

Essa política, ancorada na perspectiva do custo aluno/a qualidade (CAQ), deve fortalecer o relacionamento entre os órgãos normativos, permitindo [...] diretrizes próprias de valorização dos profissionais, bem como na definição de instrumentos básicos para o perfeito desenvolvimento do ensino, em todas as suas necessidades. [...] Articular a construçáo de projetos político-pedagógicos ${ }^{20} \mathrm{e}$ planos de desenvolvimento institucionais, sintonizados com a realidade e as necessidades locais. (BRASIL, 2010, p. 25. grifo da autora).

Entretanto, foram expostas no documento diretrizes genéricas para um compromisso político de administração democrática dos espaços públicos. Subjaz ao documento final um projeto institucional bastante genérico para a educação escolar que expressaria, nos termos de Horta (1982), o planejamento dos educadores. Entretanto, a nosso ver, o documento final da CONAE (2010) contém, pela expressão "gestão democrática", o significado forte do desenvolvimento institucional planejado. As transformaçóes operadas na sociedade brasileira, pelo vetor da expansão da governança democrática, 
produziram novos atores e formas de sociabilidade, que alteram procedimentos estabelecidos de planejamento.

[...] faz-se necessário garantir espaços articulados de decisão e deliberação coletivas para a educaçáo nacional: Fórum Nacional de Educação, fóruns estaduais, municipais e distrital de educação, Conferência Nacional de Educação, Conselho Nacional de Educação (CNE), conselhos estaduais (CEE) e municipais (CME); órgãos colegiados das instituiçōes de educação superior e conselhos escolares. (CONAE, 2010, p. 44, grifo da autora).

[...] a formação de profissionais da educação básica e superior necessita ser estabelecida por meio de uma política nacional elaborada com planos específicos, como a construção de um Referencial Curricular Nacional, em fóruns, constituídos para tal fim [...]. (CONAE, 2010, p. 79, grifo da autora).

Apoiar e garantir a criação e consolidação de conselhos estaduais e municipais, plurais e autônomos, com funçóes deliberativa, normativa e fiscalizadora, compostos, de forma paritária, por representantes dos/das trabalhadores/as da educaçâo, pais, gestores/as, estudantes, tanto do setor público quanto do privado [...]. (CONAE, 2010, p. 96, grifo da autora).

Tanto a organização da CONAE quanto a documentação que o subsidiou ou expressou denotam que apenas a ação do Estado, sem a interveniência de agentes não governamentais, é insuficiente para a elaboração e prestação de serviços capazes de operar em direção aos objetivos pretendidos. No documento final, pressupóe-se a necessidade de processos de formulação e implementação de políticas públicas como procedimentos de açóes coordenadas com a autoridade pública legítima, mas com a interveniência de outros atores sociais. Essas proposições expressariam novas formas de sociabilidade, capazes de se confrontar com a regulação de matriz burocrática, considerada como necessária para a promoção do desenvolvimento social. Ou seriam manifestações da regulação sistêmica neoclientelista? Projeta-se para os próximos dez anos um desenvolvimento capaz de articular, com semelhanças no projeto anisiano, 
uma gestão democrática das instituições educacionais e uma redução das desigualdades sociais sem mudanças no padrão de desenvolvimento.

\section{Direito à educação e outro desenvolvimento}

A expansão e a diversificação do sistema educacional brasileiro, a partir dos anos 70 do século XX, ocorreram de modo articulado a processos de concentração da riqueza e de recrudescimento da desigualdade social. Desse modo, o desenvolvimento do sistema institucional de educação no País interagiu e, por diversas maneiras, reforçou as condições sociais que o constituíram (BIHR; PFEFFERSORN, 2008). Em outras palavras, o desenvolvimento social, como nos alertava Cunha (1981a), importa em mudanças sociais mais profundas nas concepções e nos projetos desenvolvimentistas e, portanto, em planejamento integrado de mudanças no padrão em curso. Este alerta se dirige, também, ao diagnóstico de inserção soberana com inclusão social da atualidade e, especialmente, às proposiçóes de um sistema educacional unificado e uniforme em um país desigual. Políticas sociais universais implicam medidas redistributivas, que impóem perdas a grupos sociais e ganhos a outros, não necessariamente os mais necessitados. Nesse contexto, questionar o diagnóstico do desenvolvimento com inserçáo soberana importa em reter as liçôes sobre desenvolvimento social e educação.

$\mathrm{Na}$ história da educação brasileira, a associação entre educação e desenvolvimento relacionou-se à ampliaçáo do atendimento com a urgência da diversificaçáo do sistema educacional, de modo a superar uma situaçáo considerada como subdesenvolvida/atrasada/dependente. Associação presente na produçáo de educadores, sociólogos e burocratas responsáveis pelo planejamento estatal, a ampliação de matrículas e a diferenciação do atendimento (ensino adequado ao reconhecimento de identidades sociais) são consideradas na atualidade instrumentos de desenvolvimento social. $\mathrm{O}$ projeto liberal de desenvolvimento para o Brasil, na vertente exposta por Anísio Teixeira, planejava mudanças das instituiçôes educacionais de modo detalhado, prescritivo, como requisito de maior igualdade de oportunidades. Se não apresentava o questionamento ao modelo de desenvolvimento em curso no período, a ele se opunha pelo modo como projetava o sistema educacional brasileiro, o ensino público comum e o profissionalizado. No período nacionaldesenvolvimentista, suas proposiçóes articulariam o sistema educacional com 
o desenvolvimento capitalista urbano industrial mais igualitário do que aquele que se tornaria hegemônico nos anos 1970. Ao focalizar aspectos relativos ao financiamento da educação pública, em um país onde a modernização vinculou industrialização, urbanização e agronegócio, com a permanência de baixos salários, péssima distribuiçáo de renda e concentração da terra, sobre a égide do Estado, o planejamento dos educadores (HORTA, 1997) redirecionava uma parcela expressiva do fundo público.

Nesse sentido, a meta de aplicação de recursos públicos como proporção do Produto Interno Bruto (PIB), estabelecida pela CONAE (2010), implica, também, redirecionar a atuação do Estado brasileiro no sentido da reprodução ampliada da força de trabalho. Mas a expressão de Florestan Fernandes (1973), de desenvolvimento como "mudança social provocada", sinaliza para a necessária articulação com outro projeto de desenvolvimento. Nessa vertente analítica, tratar-se-ia da construção progressiva de outro desenvolvimento e, com isso, de outro sistema educacional, deslocando-se a centralidade de medidas inclusivas nesse sistema.

A crítica exposta por Pereira e Foracchi (1973) ao pensamento liberal igualitário e a de Cunha (1975) às concepçóes sobre educação como fator de desenvolvimento fundamentam-se na primazia de determinaçóes socioeconômicas nos processos de desenvolvimento, entendido como crescimento da produção. Por sua vez, o neoinstitucionalismo político vai mitigar essas determinaçóes ao atentar para as potencialidades das instituiçóes preexistentes, no sentido de redefinir alternativas e alterar a posição decisória dos atores. Ao analisar o conteúdo do documento final da CONAE (2010), verificou-se a obliteraçáo da primeira vertente analítica e o reconhecimento da segunda, especialmente no que tange aos mecanismos de financiamento da educação pública.

Com a democratização do País, projetou-se a possibilidade de um sistema educacional mais descentralizado e diverso, com gestão democrática e a defesa genérica do "planejamento participativo". Esses termos apontam, idealmente, para a interveniência de múltiplos atores na construção de outro projeto, que, por sua vez, demandaria um planejamento integral superador da visão reducionista de educação como derivaçáo do desenvolvimento, mas com ele em tensão e capaz de projetar um futuro diverso. 


\section{Notas}

1 Sobre o conceito de modos de regulação, ver Maroy (2008; 2011).

2 UNDIME - A União dos Dirigentes Municipais de Educaçâo, entidade nacional que congrega dirigentes municipais de educação, fundada em outubro de 1986, é uma associação civil sem fins lucrativos.

3 A este respeito, Maroy (2011, p. 23) afirma: "A partir de uma perspectiva de análise cognitiva das políticas públicas, podemos também considerar que as políticas educativas são influenciadas por referenciais ou modelos de regulação ou de governabilidade. Compreendemos por este fato os modelos teóricos e normativas que servem de referências cognitivas e normativas, especialmente por aqueles que decidem, na definiçẫo da 'boa maneira de pilotar ou governar' o sistema de ensino".

4 Publicada em 1964, esta obra já se encontrava na 12a edição em 1985. Marialice M. Foracchi e Luiz Pereira, professores do Departamento de Ciências Sociais da USP, eram assistentes da cátedra de Sociologia conduzida por Florestan Fernandes.

5 Conformando-se e harmonizando-se, para pensadores na tradição marxista, com as exigências determinadas pela reprodução do capital; para os liberais, pelas exigências do mercado.

6 Termo impreciso no qual a ênfase posta a uma ou mais necessidades decorria do modo de articulação efetuado em torno do binômio "educação e desenvolvimento". Horta (1982) utiliza o termo para caracterizar a emergência do planejamento educacional articulado ao planejamento setorial e global do período do nacional-desenvolvimentismo.

7 Para Cunha (1975), Anísio Teixeira trabalhou intensamente dentro do Estado para que ele assumisse a tarefa de reconstruçáo social, utilizando para isso a escola pública, obrigatória e gratuita. Nunes (2000) demarca sua obra e atuação, por uma formação apoiada na chamada pedagogia escolanovista, que contribuiu também para criar um campo de identificação dos educadores.

8 Entre os comentaristas de Anísio Teixeira, Gandini (1980) o enquadra em uma tradição liberal-conservadora de base legalístico-burocrática. Identifica-o como representante da camada industrial e considera que o projeto de Anísio 
Teixeira não se consolidou devido à emergência do Estado corporativoautoritário. Rocha (1985), por sua vez, sintetiza sua postura de intelectual orgânico, formulador de uma política congruente com interesses da burguesia industrial ascendente, setores médios e classe trabalhadora. Este mesmo autor, no posfácio a Educação é um direito (ROCHA, 1996), destaca no pensamento de Anísio Teixeira um entendimento substantivo de democracia, que o leva a atentar para a exigência de incorporação de todos os indivíduos em condições de igualdade, e nâo de forma seletiva como foi característico da cultura política de 1930, e considera ter o autor sido incansável na denúncia e na açâo contra dualismos educacionais decorrentes de uma tradição de cunho elitista em nossa história, fortemente arraigada nas profundas desigualdades sociais que aqui vicejaram desde a colonização (TEIXEIRA, 1957). Uma síntese fundamental para a apreensão do pensamento de Anísio Teixeira em relação aos seus críticos encontra-se na afirmativa de Cury (2008, p. 1192): "O trecho do Manifesto, citado no início, retoma uma passagem do livro de Anísio Teixeira, cujo título bem poderia ser a Escola capitalista no Brasil. Esse trecho denuncia a escola até então existente caracterizada por conter em si dois sistemas ou duas redes opostas".

9 Denominação genérica atribuída, muitas vezes, aos grupos sociais com capacidade de intervenção nos processos de formulação e implementação de políticas e programas governamentais, distintos do setor empresarial lucrativo.

10 A este respeito, Cury (1997, p. 17) sintetiza: "De um lado, os reformadores dirâo que, no mundo moderno, a identidade nacional supóe um avanço no e um domínio do conhecimento científico. Só aí ter-se-ia uma autonomia nacional. De outro lado, os católicos dirão que, acima de tudo isso, deverá pairar o sentimento espiritual, congregador da nação num só espírito, num só sentimento".

11 Os documentos síntese da CONAE (2010) reivindicam temas caros ao pensamento anisiano como: jornada escolar ampliada e integrada, visando à garantia de espaços e tempos apropriados às atividades educativas; e mecanismos de participação dos diferentes segmentos na instituiçáo educacional.

12 Maroy (2008), ao analisar cinco sistemas educativos europeus, aponta, simultaneamente, suas diversidades e a existência de pontos de convergência 
nas políticas educacionais. Para esse autor, políticas públicas são pensadas como resultantes de conflitos, de compromissos, da intervenção desigual de uma multiplicidade de atores e propóem ao seu analista apreendê-las em termos da ação pública, e não como obra linear da vontade ou do interesse político. Nesse sentido, o conceito de "modos regulaçáo" expressa como, em um determinado período, contexto e território, diferentes atores, de maneira diversa e desigual, articularam e coordenaram suas ações.

$13 \mathrm{O}$ artigo de Florestan Fernandes dialoga e critica os argumentos de Anísio Teixeira. Essa perspectiva é destacada por Pereira e Foracchi (1973, p. 362) ao afirmarem: "[...] o diagnóstico da situação educacional brasileira elaborado pelo sociólogo é bem mais complexo". Fernandes (1966), entretanto, destacava o diagnóstico de Anísio Teixeira sobre a situação educacional brasileira, a importância das questóes práticas por ele apresentadas e, em seguida, pôs reparos à orientação seguida pelo educador na escolha ou na recomendação dos meios.

14 Desse modo, se estabelece um diálogo e crítica com/ao artigo de Anísio Teixeira.

15 Publicado em 1975, Educação e desenvolvimento social encontrava-se em 1986 na 9ª ediçã̃o.

16 Importa reter que Cunha (1975) elabora e publica esta obra no período da ditadura militar - 1964 - 1984, aproximadamente -, especialmente quando ocorria o chamado "milagre brasileiro", com taxas de crescimento do PIB que superaram $10 \%$ ao ano e fortalecimento dos processos de concentração de renda.

17 Ver a respeito: Introdução de Cunha (1975).

18 Ao contrário do conceito de estratégia, o conceito de lógica de ação "[...] não pressupóe que os agentes estejam conscientes dos efeitos de suas escolhas, nem que atuem com um cálculo de custos, meios e benefícios, baseado em princípios racionais-instrumentais. Supóe, antes, um conceito mais alargado de racionalidade, de escolhas axiológicas conduzidas por valores e normas, não estando confinadas a processos exclusivamente instrumentais. Ela baseia-se mais no conceito de ação, atendendo a rotinas, adaptações inconscientes, reações espontâneas e a situações imprevistas" (VAN ZANTEN, 2006, p. 196). Desse modo, há que considerarem-se, ainda, 
lógicas de ação coletivas produtoras de agentes e movimentos sociais, em outros termos, capazes de configurar subjetividades coletivas.

19 A constituição de uma comissão organizadora da CONAE (BRASIL, 2010) observou a regulamentação estabelecida pelo Ministério da Educação e contou com a participação de mais de vinte entidades, entre confederações, federaçóes, sindicatos, movimentos, fóruns sociais e associações de educadores ou entidades de educação. Destaca-se, também nesta Conferência, a participação de representantes da burocracia estatal desde a organização da Conferência à redação do documento final. Uma portaria ministerial de 2008 do Ministério da Educação (Portaria Normativa $\mathrm{n}^{\mathrm{o}} 10$ [referenciar]) constituiu a comissáo organizadora da CONAE e definiu a relação das entidades que a compóem. Normas regulamentares de funcionamento foram estabelecidas pelo Secretário adjunto do MEC quanto às atribuiçóes da Comissão.

20 O documento final os reconhece como plano de desenvolvimento das instituiçóes educativas: "[...] o projeto político-pedagógico da escola (PPPE) ou no Plano de Desenvolvimento Institucional (PDI) no caso da IES" (CONAE, 2010, p. 52).

\section{REFERÊNCIAS}

ARRUDA, Maria Arminda de Nascimento. A sociologia de Florestan Fernandes. Tempo Social, São Paulo, v. 22, p. 9-27, 2010.

BIHR, Alain; PFEFFERKORN, Roland. Le système des inègalités. Paris: La Découverte, 2008.

BRASIL. CONAE 2010: Construindo o sistema nacional articulado de educação. Brasília, DF: Ministério da Educação, 2010.

CARDOSO, Miriam Limoeiro. Sobre a teorização do capitalismo dependente em Florestan Fernandes. In: FÁVERO, OSMAR. (Ed.). Democracia e educação em Florestan Fernandes. Niterói: EDUFF: Autores Associados, 2005. p. 7-40.

CUNHA, Luiz Antônio. Educação e desenvolvimento social no Brasil. Rio de Janeiro: Francisco Alves, 1975. 
CUNHA, Luiz Antônio. Sobre educação e desenvolvimento social no Brasil: crítica da crítica e autocrítica. Educação e Sociedade, Campinas, SP, n. 10, p. 123-131, set. 1981a.

CUNHA, Luiz Antônio. A organização do campo educacional: as conferências de educação. Educação e Sociedade, Campinas, SP, n. 9, p. $05-$ 48, maio 1981b.

CONFERÊNCIA NACIONAL DE EDUCAÇÃO (CONAE), 2010, Brasília, DF. Construindo o Sistema Nacional articulado de Educação: o Plano Nacional de Educaçáo, diretrizes e estratégias; Documento-Base. Brasília, DF: MEC, 2010. Disponível em <http://portal.mec.gov.br/conae/images/ stories/pdf/documento_referencia.pdf> Acesso em: 19 dez. 2011.

CURY, Carlos Roberto Jamil. A propósito de educação e desenvolvimento social no Brasil. Educação e Sociedade, Campinas, SP, n. 9, maio 1981.

CURY, Carlos Roberto Jamil. LDB e o plano nacional de educação. São Paulo: Editora do Brasil, 1997.

CURY, Carlos Roberto Jamil. Sistema nacional de educação: desafio para uma educação igualitária e federativa. Educação e Sociedade, v. 29, n. 105, p. 1187-1209, 2008.

DOMINGUES, José Maurício. Desenvolvimento, modernidade e subjetividade. Revista Brasileira de Ciências Sociais, São Paulo, v. 14, n. 40, p. 83-91, jun. 1999.

FERNANDES, Florestan. Ensaios de Sociologia geral e aplicada. São Paulo: Pioneira, 1960.

FERNANDES, Florestan. Educação e sociedade no Brasil. São Paulo: Dominus/Edusp, 1966.

FERNANDES, Florestan. O dilema educacional brasileiro. In: PEREIRA, Luiz; FORACCHI, Marialice (Org.). Educação e sociedade: leituras de Sociologia da Educação. São Paulo: Cia. Editora Nacional, 1971.

FURTADO, Celso. Desenvolvimento e política de desenvolvimento. In: PEREIRA, Luiz; FORACCHI, Marialice (Org.). Educação e sociedade: leituras de Sociologia da Educação. São Paulo: Cia. Editora Nacional, 1962.

PERSPECTIVA, Florianópolis, v. 30, n. 2, 683-718, maio/ago. 2012

http://www.perspectiva.ufsc.br 
GANDINI, Raquel Pereira Chainho. Capitalismo, tecnocracia e educação em Anísio Teixeira. Rio de Janeiro: Civilização Brasileira, 1980.

GOHN, Maria da Glória. Novas teorias dos movimentos sociais. Sáo Paulo: Loyola, 2008.

HORTA, José Silvério Baia. Liberalismo, tecnocracia e planejamento educacional no Brasil: uma contribuiçấo à história da educação brasileira no período de 1930-1970. São Paulo: Cortez, 1982

HORTA, José Silvério Baia.Plano nacional de educação: da tecnocracia à participação democrática: medo à liberdade e compromisso democrático. In: CURY, Carlos Roberto Jamil. LDB e plano nacional de educação. São Paulo: Editora do Brasil, 1997.

IANNI, Octavio. Estado e planejamento econômico no Brasil (1930 1970). 2. ed. Rio de Janeiro: Civilização Brasileira, 1977.

LASCOUMES, Pierre; LE GALÈS, Patrick. Sociologie de l'action publique. Paris: Armand Colin, 2007.

MACHADO, Luiz Toledo. A teoria da dependência na América Latina. Estudos Avançados, São Paulo, v. 13, n. 35, p. 199-215, 1999.

MAROY, Christian. Régulation des systèmes éducatives. In: VAN ZANTEN, Agnés. Dictionaire de l' éducation. Paris: PUF, 2008. p. 574578.

MAROY, Christian. Em direção a uma regulação pós-burocrática dos sistemas de ensino na Europa. In: OLIVEIRA, Dalila Andrade; DUARTE, Adriana. C. Politicas públicas e educação: regulação e conhecimento. Belo Horizonte: Fino Traço, 2011. p. 19-46.

MYRDAL, Gunnar. Teoria econômica e regiōes subdesenvolvidas. Rio de Janeiro: ISEB, 1960.

MYRDAL, Gunnar. O mundo subdesenvolvido. In: PEREIRA, Luiz; FORACCHI, Marialice (Org.). Educação e Sociedade. 6a ed. São Paulo: Cia Editora Nacional, 1973.

NUNES, Clarice. Anísio Teixeira: a poesia da ação. Bragança Paulista, SP: Edusf, 2000. 
PEREIRA, Luís. Introdução. In: PEREIRA, Luís (Org.). Desenvolvimento, trabalho e educação. Rio de Janeiro, Zahar, 1967.

PEREIRA, Luiz; FORACCHI, Marialice (Org.). Educação e sociedade: leituras de Sociologia da Educação. São Paulo: Cia Editora Nacional, 1971.

ROCHA, Marlos B. Paradigmas do moderno em educação: Francisco Campos e Anísio Teixeira. Cadernos de Pesquisa, São Paulo, n. 94, ago. 1995.

SOUZA, Celina. Estado do campo da pesquisa em políticas públicas no Brasil. Revista Brasileira de Ciências Sociais, São Paulo, v. 18, n. 51, p. 1520, fev. 2003.

SZMRECSÁNYI, Tamás. Pensamento Econômico no Brasil

Contemporâneo. Estudos avançados, São Paulo, v. 15, n. 43, 347-362, set./ dez. 2001.

TEIXEIRA, Anísio. A escola brasileira e a estabilidade social. Revista Brasileira de Estudos Pedagógicos, Brasília, DF, v. 28, n. 67, p. 3-29, jul./set. 1957.

TEIXEIRA, Anísio. Educação é um direito. São Paulo: Editora Nacional, 1968.

Teixeira, Anísio. A educação escolar no Brasil. In: PEREIRA, Luiz; FORACCHI, Marialice (Org.). Educação e Sociedade. 6. ed. São Paulo: Cia Editora Nacional, 1973.

URQUIDI, Victor L. Aspectos sociais do desenvolvimento: a educação. In: PEREIRA, Luiz; FORACCHI, Marialice (Org.). Educação e Sociedade. $6^{\mathrm{a}}$ ed. São Paulo: Cia Editora Nacional, 1973.

VAN ZANTEN, Agnés. Interdependência competitiva e as lógicas de ação das escolas: uma comparaçấo europeia. In: BARROSO, João. A regulaçấo das políticas públicas de educação: espaços, dinâmicas e atores. Lisboa, PT: Educa, 2006. p. 191-226. 


\section{Education and development: governance of educational systems}

\section{Abstract}

The current debate about the development of Brazil has received the adjective "social", in various documents. This article, through a content analysis of classic works of Brazilian educational sociology, studies the relationship between education and development. After synthesizing the sociological proposals of earlier periods, the paper analyzes three aspects of education and development found in the final document of the National Conference on Education (CONAE), held in 2010. The conference brought together about 5,000 educators, representatives from different regions of Brazil and was coordinated by the Ministry of Education. The final conference document presents proposals for the drafting of a law that establishes the National Education Plan. The diagnosis of the country's development, found in the final CONAE document, and the functions attributed to educational institutions and to the related modes of planning are analyzed from the perspective of the sociology of social regulations. The study concludes by presenting analytical resources that have been forgotten in the Conference document that guides the National Education Plan.

Keywords: Trends in educational policy. National planning meetings. Socioeconomic development.

\section{Education et développement: les modes de regulation des systèmes educatifs}

\section{Résumé}

Dans l'actualité le débat autour du développement brésilien a été qualifié de «social», dans des documents divers. Cet article, par moyen de l'analyse du contenu des ouvres classiques de la sociologie de l'éducation dans le pays, étudie comment s'est articulé le binôme «éducation et développement». La recherche, après avoir synthétisé des propositions sociologiques des périodes antérieures, analyse trois aspectes sur l'Éducation et Développement, présentes dans le document final de la Conférence National sur L'Éducation (CONAE), réalisée en 2010, au Brésil. Cette conférence a réuni environ 5.000 éducateurs des différents régions du Pays, et a été coordonné par le Ministère de l'Éducation. Le document final présente des propositions pour le développement de la Loi qui approuve le Plan d'Éducation Nationale. Le diagnostique sur le développement du Pays présente dans le document final de la CONAE, et les fonctions attribuées aux institutions d'éducation et aux moyens d'aménagement sous-jacent, sont analysés à la lumière de la sociologie des régulations sociales. L'étude est conclu en exposant des volets analytiques oubliés dans le document de la Conférence qui guident le Plan National de L'Éducation. Mots-clés: Tendances de la politique éducative. Rencontres nationaux de planification. Développement socioéconomique. 
Marisa Ribeiro Teixeira Duarte

E-mail: mmduarte@ufmg.br

Recebido em: 6/2/2012

Versáo final recebida em: 4/7/2012

Aprovado em: 5/7/2012 